\title{
Paracrine Molecules of Mesenchymal Stem Cells for Hematopoietic Stem Cell Niche
}

\author{
Tian Li and Yaojiong Wu \\ Life Science Division, Graduate School at Shenzhen, Tsinghua University, Shenzhen L406A, China \\ Correspondence should be addressed to Yaojiong Wu, wu.yaojiong@sz.tsinghua.edu.cn
}

Received 31 May 2011; Revised 26 July 2011; Accepted 26 July 2011

Academic Editor: Joseph H. Antin

Copyright () $2011 \mathrm{~T}$. Li and Y. Wu. This is an open access article distributed under the Creative Commons Attribution License, which permits unrestricted use, distribution, and reproduction in any medium, provided the original work is properly cited.

Hematopoietic stem cells (HSCs) and mesenchymal stem cells (MSCs) are both adult stem cells residing in the bone marrow. MSCs interact with HSCs, they stimulate and enhance the proliferation of HSCs by secreting regulatory molecules and cytokines, providing a specialized microenvironment for controlling the process of hematopoiesis. In this paper we discuss how MSCs contribute to HSC niche, maintain the stemness and proliferation of HSCs, and support HSC transplantation.

\section{Introduction}

Hematopoietic stem cells (HSCs) are rare cells residing in the bone marrow (BM; 1 in $10^{4}$ to 1 in $10^{8}$ of BM nucleated cells), and they are progenitors that become progressively restricted to several or single lineages. These progenitors yield blood precursors devoted to unilineage differentiation and the production of mature blood cells, including red blood cells, megakaryocytes, myeloid cells (monocyte/macrophage and neutrophil), and lymphocytes $[1,2]$. CD34 surface antigen $\left(\mathrm{CD} 34^{+}\right)$is commonly used as a marker to identify and quantify the population of progenitor cells [3], according to which, sorting HSCs from BM, peripheral blood (PB), and umbilical cord (UC)/placenta blood is relatively simple and practical $[2,4-6]$. Human HSCs are known to exhibit $\mathrm{CD} 34^{+}$, Thy $1^{+}, \mathrm{CD} 38^{\mathrm{lo} /-}, \mathrm{Ckit}^{-/ \mathrm{lo}}$, $\mathrm{CD}_{105^{+}}$, and $\mathrm{Lin}^{-}$phenotype. However, there is no general agreement on the association between any combination of these antigenic properties and function of stem cells $[3,6]$. HSCs depend on their microenvironment, the niche, for regulating self-renewal and differentiation [7]. For instance, the disruption of BMP pathway can increase the numbers of osteoblasts and HSCs $[8,9]$, and the chemokine CXCL12 regulates the cyclical release and the migration of HSCs $[10,11]$. Activation of $\beta$-catenin enforces HSCs enter cell cycle, thus leading to exhaustion of the long-term stem cell pool [12-14]. These findings suggest that signaling pathways and cellular interactions regulate the BM niche for HSCs. Besides, hypoxia regulate hematopoiesis in BM by maintaining important HSC functions and the interplay between HSCs and neighboring cells [15, 16].

Plating studies indicate that mesenchymal stem cells (MSCs) are present as a rare population of cells in the BM. They represent approximately $0.001 \%$ to $0.01 \%$ of the nucleated cells, about 10-fold less abundant than HSCs, but MSCs can be readily grown in culture [17]. Though predominantly residing in the $\mathrm{BM}$, MSCs also present similar but not identical features in many other tissues such as blood, placenta, dental pulp, and adipose tissue. MSCs have the potential to differentiate into multiple phenotypes such as osteoblasts, chondrocytes, adipocytes, neural cells, and probably other cell lineages [18-21]. International Society for Cellular Therapy (ISCT) has provided the following minimum criteria for defining multipotent mesenchymal stromal cells as follows: plastic-adherent under standard culture conditions; express CD105, CD73, and CD90 and lack expression of CD45, CD34, CD14, or CD11b, CD79 or CD19 and HLA-DR, and must differentiate into osteoblasts, adipocytes, and chondroblasts in vitro [22].

$\mathrm{BM}$ has received the most attention because it carries MSCs as well as HSCs. Evidence indicates that MSCs are key component of the HSC niche in the BM where these two distinct stem cell populations arrange closely, ensuring hematopoietic and skeletal homeostasis [18]. MSCs interact with HSCs, secreting chemokines that contribute to HSC niche and support long-term growth of HSCs [23, 24]. 
TABLE 1: The cytokines secreted by MSCs that regulate HSCs.

\begin{tabular}{|c|c|c|}
\hline Cytokines & Function & References \\
\hline CXCL12 & $\begin{array}{l}\text { Regulate the adhesion, expansion, } \\
\text { migration, and homing of HSCs }\end{array}$ & {$[10,11,28-32]$} \\
\hline$(\mathrm{SDF}-1)$ & $\begin{array}{l}\text { Reduce the production of } \\
\text { inflammatory cytokines and } \\
\text { chemokines }\end{array}$ & {$[33]$} \\
\hline FL & $\begin{array}{l}\text { Maintain HSC proliferation and } \\
\text { self-renewal, regulate } \\
\text { hematopoietic growth }\end{array}$ & {$[28]$} \\
\hline IL-6, TPO & $\begin{array}{l}\text { Influence HSC proliferation and } \\
\text { differentiation }\end{array}$ & {$[29,34]$} \\
\hline GM-CSF & Regulate HSC engraftment & {$[35]$} \\
\hline \multirow{3}{*}{ SCF } & $\begin{array}{l}\text { Maintain HSC proliferation and } \\
\text { self-renewal }\end{array}$ & \\
\hline & Regulate hematopoietic growth & {$[28,36]$} \\
\hline & Regulate HSC engraftment & {$[35]$} \\
\hline $\begin{array}{l}\text { VCAM1, } \\
\text { E-selectin, } \\
\text { collagen I, } \\
\text { fibronectin }\end{array}$ & $\begin{array}{l}\text { Regulate HSC homing and } \\
\text { adhesion }\end{array}$ & {$[35,37]$} \\
\hline
\end{tabular}

MSCs can be cotransplanted with HSCs to improve their engraftment [25-27] (Table 1).

\section{Mesenchymal Stem Cells Contribute to Hematopoietic Stem Cell Niche}

The term "niche" for the specific HSC BM microenvironment was first coined in 1978, proposing that HSCs are in intimate contact with the bone, which was responsible for the apparently unlimited capacity of HSCs' proliferation and the inhibition of HSCs' maturation [38]. Niches exist within the $\mathrm{BM}$ which preserve specific aspects of hematopoiesis, such as HSC survival, self-renewal, and differentiation, supporting the maintenance of the blood system under normal and stressed conditions [39]. Research has made it increasingly clear that the stem cell niches provide a microenvironment which is important in protecting the self-renewing, undifferentiated state of their residents [40]. Three types of HSC niches have been hypothesized, defined according to the HSC uniformity [18, 41]. Two of these proposed niches are provided by cells directly descending from MSCs: the osteoblastic niche, where HSCs reside in close contact with endosteal cells [8], and the reticular stromal niche, where HSCs reside in close contact with stromal cells which are also known as mural cells or pericytes, the smooth muscle cells lining arteriolar side of the sinusoids [42]. The third proposed niche is the vascular/sinusoidal niche, where HSCs reside in direct contact with endothelial cells in the venous side of the sinusoids [43]. It is well known that HSC circulation involves HSCs leaving the BM, entering the vascular system (mobilization), and returning to the $\mathrm{BM}$ (homing) [44, 45]. The BM vascular structure provides a barrier between the hematopoietic compartment and the peripheral circulation. Most primitive HSCs remain physiologically quiescent within the BM niche; however, a portion of HSCs leave this resting pool and start the process of mobilization [39, 46-48].

Studies showed that both mouse and human osteoblast cell lines secreted a large number of cytokines that promote the proliferation of haematopoietic cells in culture, proving that cells involved in bone formation have stem-cellsupporting activity $[49,50]$. MSCs reside in the bone cavity and are proposed to give rise to the majority of marrow stromal cell lineages, including chondrocytes, osteoblasts, and adipocytes, as suggested in numerous studies [48-50]. MSCs and HSCs form a structurally unique niche in the $\mathrm{BM}$, which is regulated by local input from the surrounding microenvironment, and long-distance cues from hormones and the autonomic nervous system [51]. MSCs isolated from BM produce several growth factors and chemokines, such as CXCL12 (SDF-1), stem cell factor (SCF), Flt-3 ligand (FL), thrombopoietin (TPO), interleukin (IL)-6, IL11, leukemia inhibitory factor (LIF), macrophage colonystimulating factor (M-CSF), tumor necrosis factor- (TNF-) $\alpha$, and transforming growth factor- (TGF-) $\beta 1[28,52-54]$. HSCs are reduced in the BM after the depletion of MSCs, owing at least in part to mobilization towards extramedullary sites [51]. Loss of SCF from supporting cells or the receptor in HSCs leads to hematopoietic failure, indicating MSCs play an essential role in HSC niche function [36]. SCF and FL are implicated in maintaining HSC proliferation and self-renewal, regulating hematopoietic growth [28]. IL3 or IL- 6 combined with TPO signaling can influence HSC proliferation and differentiation $[29,34]$. Besides, as mentioned previously, the chemokine CXCL12 interacts with its receptor CXCR4, regulates the cyclical release of HSCs, the migration of HSCs to the vascular niche from BM, and the homing of HSCs to the BM $[10,11,29-32]$, and promotes adhesive interactions between HSCs and stromal cells [55]. In addition, CXCL12 chemokine signaling pathway contribute to the ex vivo expansion of HSCs [28]. Moreover, CXCL12 mediates angiogenic responses, promotes differentiation of $\mathrm{CD}_{3} 4^{+}$cells to endothelial progenitor cells, and appears to affect many other factors, including G-CSF, VEGF, and CXCL16 that relate to HSC mobilization and homing [33]. However, only $\beta$-catenin-activated MSCs but not naïve MSCs have stimulatory effect on HSC self-renewal in vivo [56].

\section{The Effect of Mesenchymal Stem Cell on the Maintenance of Hematopoietic Stem Cells}

Coculture of HSCs with MSCs might be an ideal method for maintaining the HSC pluripotency, because the growth or survival signals might be transferred to the HSC via adhesive molecules by modulating the cytokines and growth factor-dependent signals [57]. 5-aza-deoxycytidine (aza-D) and trichostatin A (TSA) have potent activity to maintain the stemness of HSCs, being candidate additives for HSCs ex vivo expansion, but they can also cause serious cell death $[58,59]$. Koh et al. examined the effects of MSCs on the maintenance of CD $34^{+}$cells driven by aza-D and TSA in culture with the combined cytokines, and found that the total cell number 
of HSCs cultured with MSCs was higher in aza-D or TSA than in any culture conditions without MSCs, while most of HSCs cultured with cytokine treatment but without MSCs would lose their pluripotency and then differentiate, though they were induced to proliferate effectively [60]. It suggested that the co-culture of $\mathrm{CD}_{3}{ }^{+}$cells with MSCs might not simply deliver the proliferation signals but also stemness and survival signals, and overlap the action of epigenetic regulators $[57,60]$.

\section{Application of Bone Marrow Mesenchymal Stem Cells in Hematopoietic Stem Cell Transplantation}

HSCs were primarily used in the treatment of patients with hematological malignancies. During the course of treatment, patients' cancerous cells are first destroyed by chemo/radiotherapy and then replaced with $\mathrm{BM}$ or $\mathrm{PB} / \mathrm{G}$ CSF transplant from a human leukocyte antigen- (HLA-) matched donor $[61,62]$. In most cases, autologous HSCs are collected prior to the treatment and reinfused into the patients, but the patient's cancerous cells may be inadvertently collected and reinfused back into the patients along with HSCs [63]. Allogeneic marrow transplants have also been used in the treatment of hereditary blood disorders including aplastic anemia, $\beta$-thalassemia, Wiskott-Aldrich syndrome, and SCID, as well as inborn errors of metabolism disorders such as Hunter's syndrome and Hurler's syndrome [64-68]. One of the major challenges with HSC transplants is failure to engraft, which is mediated by donor T cells as a result of graft-versus-host disease (GVHD). Graft-versustumor effect of allogeneic HSC transplants may be a result of an immune reaction between donor cytotoxic $\mathrm{T}$ cells and patient's malignant cells [69]. MSCs are known to interact with HSCs and immune cells, and represent potential cellular therapy to enhance allogeneic hematopoietic engraftment and prevent GVHD [70-72]. Coculture of MSCs and HSCs could cause a significantly increase in $\mathrm{CD}^{+} 4^{+}$cells [73]. Aside from BM-derived MSCs, MSCs from adipose tissue can also be applied in hematopoietic engraftment, which would be an innovative supplement for cellular therapies [74, 75].

Cotransplantation studies in animal models as well as in humans showed that primary or culture-expanded MSCs promote the engraftment of HSCs. Cotransplantation of MSCs and cord blood or mobilized peripheral blood CD $34^{+}$ cells resulted in a significantly higher level of engraftment than transplantation of $\mathrm{CD} 34^{+}$cells only $[35,37,76-81]$. This enhancement was greater after cotransplantation of GM-CSF and SCF-transfected MSCs, indicating that these growth factors relate to engraftment, though the mechanism of the enhancing effect is still unknown [35]. It is likely that the ability to promote engraftment is maintained along lineage differentiation [76]. Several lines of evidence suggest that MSCs produce several essential hematopoietic growth factors, adhesion molecules [28, 52-54], and extracellular matrix (ECM) proteins (such as VCAM1, E-selectin, collagen I, and fibronectin) that are known to play an important role in HSC homing $[35,37]$. Selective adhesion of progenitors and cytokines to ECM components or stromal cells then result in the colocalization of progenitors at a specific stage of differentiation with a specific array of cytokines in sotermed niches [77]. This provides a level of growth and differentiation regulation [37]. Although it would mean exposure to allogeneic donor antigens, allogeneic MSCs can provide equal enhancement of engraftment as autologous cells. Cotransplanted MSCs shift the differentiation pattern from a lymphoid to a myeloid predominance and enhance megakaryocytic engraftment [78]. The cotransplantation of HSCs and MSCs enhanced engraftment as the dose of MSCs increased whereas an excessive dose of MSCs might decrease engraftment efficiency [79]. Besides, human allogeneic MSC layers in a serum-free culture system enabled the ex vivo expansion/maintenance of human HSCs [80], which indicates that MSCs may be used as a universal and reproducible stromal feeder layer to efficiently expand and maintain human BM HSCs ex vivo [81].

MSCs produce a microenvironment supporting hematopoiesis and may contribute to immune tolerance because of low immunogenicity and the suppressive effect of alloreactivity [75, 82]. MSCs had a potent immunosuppressive effect in vivo after allogeneic stem-cell transplantations [26]. The CXCL12- $\alpha$ secreted by MSCs could reduce the production of a variety of inflammatory cytokines and chemokines, including IL-13, IL-3 R $\beta$, IL-4, IL-5, IL-9, IL-10, L-selectin, MIP-3 $\alpha / \beta$, TCA3/CCL1, TNF-a, IL- $1 \beta$, lymphotactin/CXCL1, L-selectin, leptin receptor, eotaxin-2, CTACK/CCL27, CRG-2/CXCL10, and CD30L [33]. In allogeneic transplantation, the simultaneous infusion of MSCs may promote hematopoietic engraftment across the major histocompatibility complex (MHC) barrier and decrease the incidence of GVHD, even though the exact mechanisms have not been clarified [83-85]. MSCs are lack of MHC class II and most of classical costimulatory molecules $[86,87]$. Moreover, MSCs directly inhibit the expansion and activation of alloreactive Tlymphocytes and this T cell-suppressive effect may have important therapeutic implications in preventing or treating acute and chronic GVHD [70]. MSCs can significantly reduced the expression of activation markers CD25 (interleukn-2 receptor), CD38, and CD69 on phytohaemagglutinin- (PHA-) stimulated lymphocytes, making allogeneic HSCs and MSCs escape from recognition by alloreactive T-cells, because the expression of CD25 (IL-2 receptor), CD38 and CD69 was unchanged. Besides, MSC suppressed the proliferation of PHA-stimulated $\mathrm{CD}^{+}$, $\mathrm{CD}^{+}$, and $\mathrm{CD}^{+}$lymphocytes [87-89]. However, MSCs inhibit naïve and memory T-cell responses to their cognate antigens by the engagement of the inhibitory molecule PD-1 while the expression of MHC molecules and the presence in culture of antigen-presenting cells (APCs) or $\mathrm{CD} 4^{+} / \mathrm{CD} 25^{+}$ regulatory $\mathrm{T}$ cells were not required for MSCs to inhibit preferentially [87-91]. MSCs can regulate B-cell functions including migration, proliferation, and immunoglobulin(Ig) synthesis. For example, MSCs inhibit the proliferation of Bcells by arresting them at G0/G1 phase of the cell cycle, and the production of IgM, IgA, and IgG of B-cells [88, 92]. Dendritic cells (DCs) play an important role in supporting antigen-specific $\mathrm{CD} 4^{+}$T-cell proliferation and modulating 


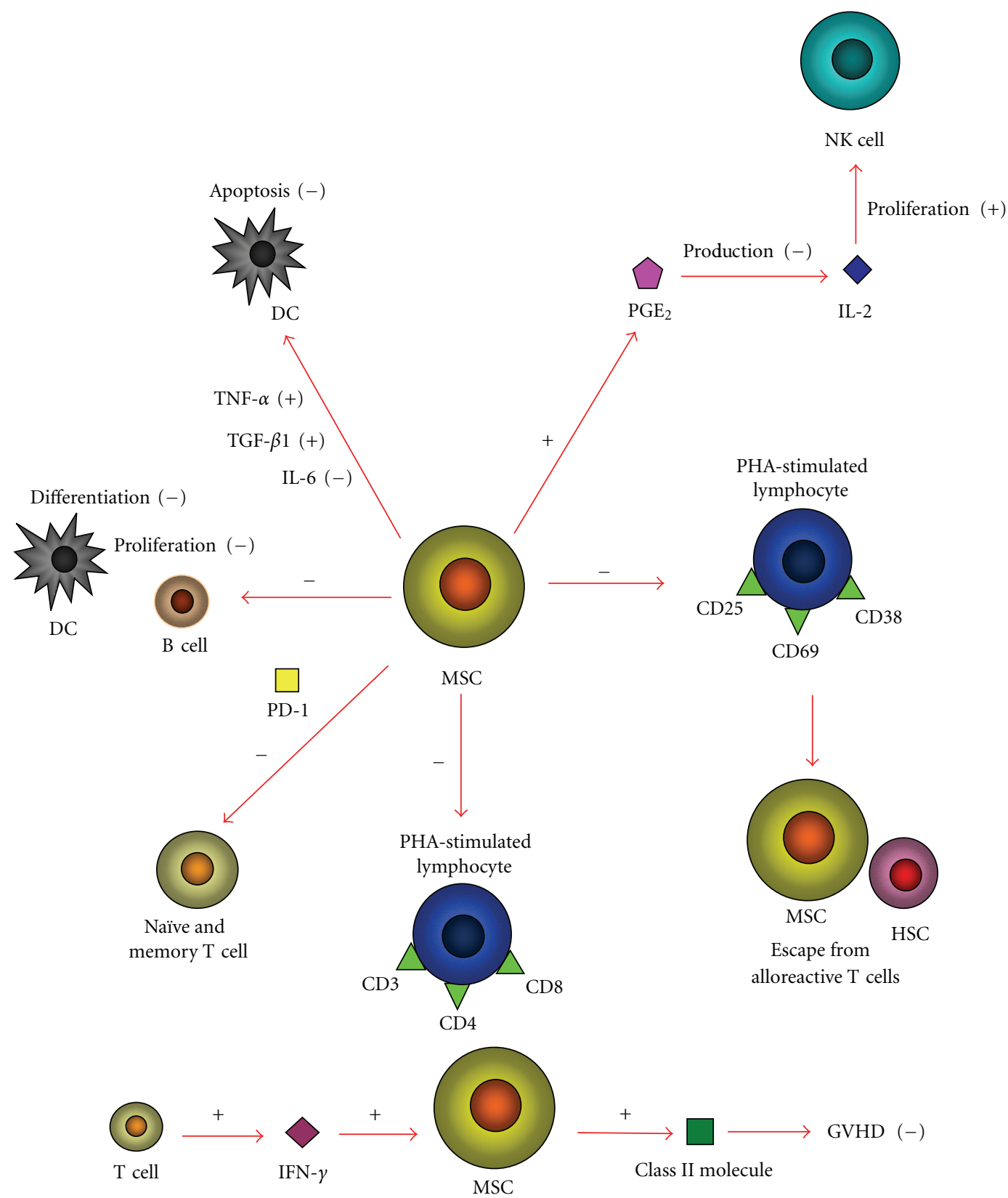

Figure 1: MSCs interact with immune cells, representing potential cellular therapy to enhance allogeneic hematopoietic engraftment and prevent GVHD. MSCs reduced the expression of activation markers CD25, CD38 and CD69 on PHA-stimulated lymphocytes, making allogeneic HSCs and MSCs escape from recognition of alloreactive T-cells. MSCs suppressed the proliferation of PHA-stimulated CD3+, CD4+ and CD8+ lymphocytes. MSCs inhibit naïve and memory T-cell responses to their cognate antigens by the engagement of the inhibitory molecule PD-1. MSCs inhibit the proliferation of B-cells and the differentiation of mature DCs from HSCs. MSCs induce DC apoptosis by downregulate TNF- $\alpha$ and TGF- $\beta 1$ levels and upregulated IL- 6 levels. MSCs inhibit the IL-2-induced proliferation of NK cells by producing PGE2. IFN- $\gamma$ can stimulate MSCs to exhibit induction of class II molecule expression to prevent GVHD.

diverse T-cell responses including GVHD [93]. MSCs can inhibit the differentiation of mature DCs from HSCs by arresting them at the precursor stage, interfere with DC antigen presentation, prevent DC migration ability, and induce DC apoptosis by downregulate TNF- $\alpha$ and TGF- $\beta 1$ levels and upregulated IL-6 levels [93-95]. IFN- $\gamma$, which is produced by donor T-cells in response to antigen recognition, displays natural cytolytic activity against the cells missing markers of self-MHC class I, serves as an initiating stimulus for MSC immunosuppressive activity in vivo [88]. This indicates that the exposure to concentrated amounts of IFN- $\gamma$ of MSCs can stimulate MSCs to exhibit induction of class II molecule expression, to prevent GVHD and provide the basis for a new potential strategy in prevention of GVHD $[87-89,96]$. There is also evidences that MSCs can inhibit the IL-2-induced proliferation of natural killer 
(NK) cells by producing prostaglandin $\mathrm{E}_{2}\left(\mathrm{PGE}_{2}\right)$, a product of arachidonic acid metabolism that acts as a powerful immune suppressant, and inhibits T-cell mitogenesis and IL2 production $[88,97,98]$ (Figure 1).

\section{Conclusion}

Lines of evidence have indicated that MSCs are capable of supporting the expansion and differentiation of HSCs and enhancing hematopoietic engraftment in the past two decades, but the exact mechanisms by how MSCs support HSCs are still unclear. MSCs may affect HSCs by producing growth factors and chemokines that take parts in signaling pathways regulating HSCs. Meanwhile, HSCs interact with MSCs though this has been less understood. MSCs can home to injured tissues when coinfused with HSCs [99]. A better understanding of the interaction between MSCs and HSCs will substantially ultimately help develop novel therapies for hematopoietic diseases.

\section{Acknowledgment}

This paper was supported by grants from Natural Science Foundation of China (nos. 30871273, 30971496, and U1032003) and from Shenzhen (JC201005280597A) to Y. Wu.

\section{References}

[1] S. H. Orkin and L. I. Zon, "Hematopoiesis: an evolving paradigm for stem cell biology," Cell, vol. 132, no. 4, pp. 631644, 2008.

[2] Group SCTC, "Allogeneic peripheral blood stem-cell compared with bone marrow transplantation in the management of hematologic malignancies: an individual patient data meta-analysis of nine randomized trials," Journal of Clinical Oncology, vol. 23, no. 22, pp. 5074-5087, 2005.

[3] L. Murray, B. Chen, A. Galy et al., "Enrichment of human hematopoietic stem cell activity in the CD34 $4^{+}$Thy- $1^{+}$Lin subpopulation from mobilized peripheral blood," Blood, vol. 85, no. 2, pp. 368-378, 1995.

[4] N. Flomenberg, S. M. Devine, J. F. DiPersio et al., "The use of AMD3100 plus G-CSF for autologous hematopoietic progenitor cell mobilization is superior to G-CSF alone," Blood, vol. 106, no. 5, pp. 1867-1874, 2005.

[5] E. Gluckman, H. A. Broxmeyer, A. D. Auerbach et al., "Hematopoietic reconstitution in a patient with Fanconi's anemia by means of umbilical-cord blood from an HLAidentical sibling," New England Journal of Medicine, vol. 321, no. 17, pp. 1174-1178, 1989.

[6] L. Pierelli, G. Scambia, G. Bonanno et al., "CD34 $/ \mathrm{CD} 105^{+}$ cells are enriched in primitive circulating progenitors residing in the G0 phase of the cell cycle and contain all bone marrow and cord blood CD $34^{+} / \mathrm{CD} 38^{\text {low/- }}$ precursors," British Journal of Haematology, vol. 108, no. 3, pp. 610-620, 2000.

[7] S. J. Morrison and A. C. Spradling, "Stem cells and niches: mechanisms that promote stem cell maintenance throughout life," Cell, vol. 132, no. 4, pp. 598-611, 2008.

[8] L. M. Calvi, G. B. Adams, K. W. Weibrecht et al., "Osteoblastic cells regulate the haematopoietic stem cell niche," Nature, vol. 425, no. 6960, pp. 841-846, 2003.
[9] J. W. Zhang, C. Niu, L. Ye et al., "Identification of the haematopoietic stem cell niche and control of the niche size," Nature, vol. 425, no. 6960, pp. 836-841, 2003.

[10] S. Méndez-Ferrer, D. Lucas, M. Battista, and P. S. Frenette, "Haematopoietic stem cell release is regulated by circadian oscillations," Nature, vol. 452, no. 7186, pp. 442-447, 2008.

[11] T. Sugiyama, H. Kohara, M. Noda, and T. Nagasawa, "Maintenance of the hematopoietic stem cell pool by CXCL12-CXCR4 chemokine signaling in bone marrow stromal cell niches," Immunity, vol. 25, no. 6, pp. 977-988, 2006.

[12] M. Scheller, J. Huelsken, F. Rosenbauer et al., "Hematopoietic stem cell and multilineage defects generated by constitutive $\beta$-catenin activation," Nature Immunology, vol. 7, no. 10, pp. 1021-1023, 2006.

[13] T. Suda and F. Arai, "Wnt signaling in the niche," Cell, vol. 132, no. 5, pp. 729-730, 2008.

[14] H. E. Fleming, V. Janzen, C. L. Celso et al., "Wnt signaling in the niche enforces hematopoietic stem cell quiescence and is necessary to preserve self-renewal in vivo," Cell Stem Cell, vol. 2, no. 3, pp. 274-283, 2008.

[15] P. Eliasson and J. Jönsson, "The hematopoietic stem cell niche: low in oxygen but a nice place to be," Journal of Cellular Physiology, vol. 222, no. 1, pp. 17-22, 2010.

[16] K. Hosokawa, F. Arai, H. Yoshihara et al., "Function of oxidative stress in the regulation of hematopoietic stem cell-niche interaction," Biochemical and Biophysical Research Communications, vol. 363, no. 3, pp. 578-583, 2007.

[17] M. F. Pittenger and B. J. Martin, "Mesenchymal stem cells and their potential as cardiac therapeutics," Circulation Research, vol. 95, no. 1, pp. 9-20, 2004.

[18] M. Valtieri and A. Sorrentino, "The mesenchymal stromal cell contribution to homeostasis," Journal of Cellular Physiology, vol. 217, no. 2, pp. 296-300, 2008.

[19] G. Kögler, S. Sensken, J. A. Airey et al., "A new human somatic stem cell from placental cord blood with intrinsic pluripotent differentiation potential," Journal of Experimental Medicine, vol. 200, no. 2, pp. 123-135, 2004.

[20] T. Tondreau, L. Lagneaux, M. Dejenefle et al., "Bone marrowderived mesenchymal stem cells already express specific neural proteins before any differentiation," Differentiation, vol. 72, no. 7, pp. 319-326, 2004.

[21] J. E. Dennis and P. Charbord, "Origin and differentiation of human and murine stroma," Stem Cells, vol. 20, no. 3, pp. 205214, 2002.

[22] M. Dominici, K. Le Blanc, I. Mueller et al., "Minimal criteria for defining multipotent mesenchymal stromal cells. The International Society for Cellular Therapy position statement," Cytotherapy, vol. 8, no. 4, pp. 315-317, 2006.

[23] E. Imai and T. Ito, "Can bone marrow differentiate into renal cells?” Pediatric Nephrology, vol. 17, no. 10, pp. 790-794, 2002.

[24] S. T. Mohanty, L. Kottam, A. Gambardella et al., "Alterations in the self-renewal and differentiation ability of bone marrow mesenchymal stem cells in a mouse model of rheumatoid arthritis," Arthritis Research and Therapy, vol. 12, no. 4, p. R149, 2010.

[25] O. N. Koç, S. L. Gerson, B. W. Cooper et al., "Rapid hematopoietic recovery after coinfusion of autologous-blood stem cells and culture-expanded marrow mesenchymal stem cells in advanced breast cancer patients receiving high-dose chemotherapy," Journal of Clinical Oncology, vol. 18, no. 2, pp. 307-316, 2000.

[26] K. L. Blanc, I. Rasmusson, B. Sundberg et al., "Treatment of severe acute graft-versus-host disease with third party 
haploidentical mesenchymal stem cells," Lancet, vol. 363, no. 9419, pp. 1439-1441, 2004.

[27] S. Aggarwal and M. F. Pittenger, "Human mesenchymal stem cells modulate allogeneic immune cell responses," Blood, vol. 105, no. 4, pp. 1815-1822, 2005.

[28] S. Mishima, A. Nagai, S. Abdullah et al., "Effective ex vivo expansion of hematopoietic stem cells using osteoblastdifferentiated mesenchymal stem cells is CXCL12 dependent," European Journal of Haematology, vol. 84, no. 6, pp. 538-546, 2010.

[29] J. Zhang and L. Li, "Stem cell niche: microenvironment and beyond," Journal of Biological Chemistry, vol. 283, no. 15, pp. 9499-9503, 2008.

[30] M. L. Burness and D. A. Sipkins, "The stem cell niche in health and malignancy," Seminars in Cancer Biology, vol. 20, no. 2, pp. 107-115, 2010.

[31] B. S. Lam and G. B. Adams, "Hematopoietic stem cell lodgment in the adult bone marrow stem cell niche," International Journal of Laboratory Hematology, vol. 32, no. 6, pp. 551-558, 2010.

[32] J. M. Burns, B. C. Summers, Y. Wang et al., "A novel chemokine receptor for SDF-1 and I-TAC involved in cell survival, cell adhesion, and tumor development," Journal of Experimental Medicine, vol. 203, no. 9, pp. 2201-2213, 2006.

[33] P. T. Thevenot, A. M. Nair, J. Shen, P. Lotfi, C. Y. Ko, and L. Tang, "The effect of incorporation of SDF- $1 \alpha$ into PLGA scaffolds on stem cell recruitment and the inflammatory response," Biomaterials, vol. 31, no. 14, pp. 3997-4008, 2010.

[34] I. Rappold, S. M. Watt, N. Kusadasi, S. Rose-John, J. Hatzfeld, and R. E. Ploemacher, "Gp130-signaling synergizes with FL and TPO for the long-term expansion of cord blood progenitors,” Leukemia, vol. 13, no. 12, pp. 2036-2048, 1999.

[35] J. Y. Han, R. Y. Goh, S. Y. Seo et al., "Cotransplantation of cord blood hematopoietic stem cells and culture-expanded and GM-CSF-/SCF-transfected mesenchymal stem cells in SCID mice," Journal of Korean Medical Science, vol. 22, no. 2, pp. 242-247, 2007.

[36] A. Bernstein, L. Forrester, A. D. Reith, P. Dubreuil, and R. Rottapel, "The murine W/c-kit and steel loci and the control of hematopoiesis," Seminars in Hematology, vol. 28, no. 2, pp. 138-142, 1991.

[37] M. Verfaillie, "Adhesion receptors as regulators of the hematopoietic process," Blood, vol. 92, no. 8, pp. 2609-2612, 1998.

[38] R. Schofield, "The relationship between the spleen colonyforming cell and the haemopoietic stem cell," Blood Cells, vol. 4, no. 1-2, pp. 7-25, 1978.

[39] R. W. Garrett and S. G. Emerson, "Bone and blood vessels: the hard and the soft of hematopoietic stem cell niches," Cell Stem Cell, vol. 105, no. 4, pp. 503-506, 2009.

[40] E. Fuchs, T. Tumbar, and G. Guasch, "Socializing with the neighbors: stem cells and their niche," Cell, vol. 116, no. 6, pp. 769-778, 2004.

[41] F. Fierro, T. Illmer, D. Jing et al., "Inhibition of platelet-derived growth factor receptor- $\beta$ by imatinib mesylate suppresses proliferation and alters differentiation of human mesenchymal stem cells in vitro," Cell Proliferation, vol. 40, no. 3, pp. 355366, 2007.

[42] B. Sacchetti, A. Funari, S. Michienzi et al., "Self-renewing osteoprogenitors in bone marrow sinusoids can organize a hematopoietic microenvironment," Cell, vol. 131, no. 2, pp. 324-336, 2007.
[43] M. J. Kiel, O. H. Yilmaz, T. Iwashita, O. H. Yilmaz, C. Terhorst, and S. J. Morrison, "SLAM family receptors distinguish hematopoietic stem and progenitor cells and reveal endothelial niches for stem cells," Cell, vol. 121, no. 7, pp. 1109-1121, 2005.

[44] T. Yin and L. Li, “The stem cell niches in bone," Journal of Clinical Investigation, vol. 116, no. 5, pp. 1195-1201, 2006.

[45] M. H. Raaijmakers, "Regulating traffic in the hematopoietic stem cell niche," Haematologica, vol. 95, no. 9, pp. 1439-1441, 2010.

[46] B. Heissig, K. Hattori, S. Dias et al., "Recruitment of stem and progenitor cells from the bone marrow niche requires MMP-9 mediated release of Kit-ligand," Cell, vol. 109, no. 5, pp. 625637, 2002.

[47] F. Arai, A. Hirao, M. Ohmura et al., "Tie2/angiopoietin-1 signaling regulates hematopoietic stem cell quiescence in the bone marrow niche," Cell, vol. 118, no. 2, pp. 149-161, 2004.

[48] Y. Xie, T. Yin, W. Wiegraebe et al., "Detection of functional haematopoietic stem cell niche using real-time imaging," Nature, vol. 457, no. 7225, pp. 97-101, 2009.

[49] R. S. Taichman and S. G. Emerson, "The role of osteoblasts in the hematopoietic microenvironment," Stem Cells, vol. 16, no. 1, pp. 7-15, 1998.

[50] Y. Muguruma, T. Yahata, H. Miyatake et al., "Reconstitution of the functional human hematopoietic microenvironment derived from human mesenchymal stem cells in the murine bone marrow compartment," Blood, vol. 107, no. 5, pp. 18781887, 2006.

[51] S. Méndez-Ferrer, T. V. Michurina, F. Ferraro et al., "Mesenchymal and haematopoietic stem cells form a unique bone marrow niche," Nature, vol. 466, no. 12, pp. 829-834, 2010.

[52] M. K. Majumdar, M. A. Thiede, S. E. Haynesworth, S. P. Bruder, and S. L. Gerson, "Human marrow-derived mesenchymal stem cells (MSCs) express hematopoietic cytokines and support long-term hematopoiesis when differentiated toward stromal and osteogenic lineages," Journal of Hematotherapy and Stem Cell Research, vol. 9, no. 6, pp. 841-848, 2000.

[53] L. Shi and L. H. Hu, "The normal flora may contribute to the quantitative preponderance of myeloid cells under physiological conditions," Medical Hypotheses, vol. 21, no. 12, pp. 141-143, 2011.

[54] K. S. Jeltsch, T. F. Radke, S. Laufs et al., "Unrestricted somatic stem cells: interaction with $\mathrm{CD} 34^{+}$cells in vitro and in vivo, expression of homing genes and exclusion of tumorigenic potential," Cytotherapy, vol. 13, no. 3, pp. 357-365, 2011.

[55] B. B. Ratliff, N. Singh, K. Yasuda et al., "Mesenchymal stem cells, used as bait, disclose tissue binding sites," American Journal of Pathology, vol. 177, no. 2, pp. 873-883, 2010.

[56] J. Y. Ahn, G. Park, J. S. Shim, J. W. Lee, and I. H. $\mathrm{Oh}$, "Intramarrow injection of $\beta$-catenin-activated, but not naïve mesenchymal stromal cells stimulates self-renewal of hematopoietic stem cells in bone marrow," Experimental and Molecular Medicine, vol. 42, no. 2, pp. 122-131, 2010.

[57] M. Tavassoli and A. Friedenstein, "Hemopoietic stromal microenvironment," American Journal of Hematology, vol. 15, no. 2, pp. 195-203, 1983.

[58] P. A. Marks, V. M. Richon, and R. A. Rifkind, "Histone deacetylase inhibitors: inducers of differentiation or apoptosis of transformed cells," Journal of the National Cancer Institute, vol. 92, no. 15, pp. 1210-1216, 2000.

[59] A. P. Wolffe, P. L. Jones, and P. A. Wade, "DNA demethylation," Proceedings of the National Academy of Sciences of the United States of America, vol. 96, no. 11, pp. 5894-5896, 1999. 
[60] S. H. Koh, H. S. Choi, E. S. Park, H. J. Kang, H. S. Ahn, and H. Y. Shin, "Co-culture of human CD $34^{+}$cells with mesenchymal stem cells increases the survival of $\mathrm{CD} 34^{+}$cells against the 5-aza-deoxycytidine- or trichostatin A-induced cell death," Biochemical and Biophysical Research Communications, vol. 329, no. 3, pp. 1039-1045, 2005.

[61] M. Tabata, A. Satake, N. Okura et al., "Long-term outcome after allogeneic bone marrow transplantation for hematological malignancies with non-remission status. Results of a single-center study of 24 patients," Annals of Hematology, vol. 81, no. 10, pp. 582-587, 2002.

[62] L. M. Ball, M. E. Bernardo, H. Roelofs et al., "Cotransplantation of ex vivo-expanded mesenchymal stem cells accelerates lymphocyte recovery and may reduce the risk of graft failure in haploidentical hematopoietic stem-cell transplantation," Blood, vol. 110, no. 7, pp. 2764-2767, 2007.

[63] S. Hombach-Klonisch, S. Panigrahi, I. Rashedi et al., "Adult stem cells and their trans-differentiation potentialperspectives and therapeutic applications," Journal of Molecular Medicine, vol. 86, no. 12, pp. 1301-1314, 2008.

[64] R. Iannone, J. F. Casella, E. J. Fuchs et al., "Results of minimally toxic nonmyeloablative transplantation in patients with sickle cell anemia and $\beta$-thalassemia," Biology of Blood and Marrow Transplantation, vol. 9, no. 8, pp. 519-528, 2003.

[65] S. Y. Pai, D. DeMartiis, C. Forino et al., "Stem cell transplantation for the Wiskott-Aldrich syndrome: a single-center experience confirms efficacy of matched unrelated donor transplantation," Biology of Blood and Marrow Transplantation, vol. 38, no. 10, pp. 671-679, 2006.

[66] C. Peters and W. Krivit, "Hematopoietic cell transplantation for mucopolysaccharidosis IIB (Hunter syndrome)," Bone Marrow Transplantation, vol. 25, no. 10, pp. 1097-1099, 2000.

[67] M. Salerno, R. Busiello, V. Esposito et al., "Allogeneic bone marrow transplantation restores IGF-I production and linear growth in a $\gamma$-SCID patient with abnormal growth hormone receptor signaling," Bone Marrow Transplantation, vol. 33, no. 7, pp. 773-775, 2004.

[68] S. L. Staba, M. L. Escolar, M. Poe et al., "Cord-blood transplants from unrelated donors in patients with hurler's syndrome," New England Journal of Medicine, vol. 350, no. 19, pp. 1960-1969, 2004.

[69] T. Kurokawa, K. Fischer, H. Bertz, S. Hoegerle, J. Finke, and A. Mackensen, "In vitro and in vivo characterization of graftversus-tumor responses in melanoma patients after allogeneic peripheral blood stem cell transplantation," International Journal of Cancer, vol. 101, no. 1, pp. 52-60, 2002.

[70] B. Maitra, E. Szekely, K. Gjini et al., "Human mesenchymal stem cells support unrelated donor hematopoietic stem cells and suppress T-cell activation," Bone Marrow Transplantation, vol. 33, no. 6, pp. 597-604, 2004.

[71] I. Resnick, P. Stepensky, G. Elkin et al., "MSC for the improvement of hematopoietic engraftment," Bone Marrow Transplantation, vol. 45, no. 3, pp. 605-606, 2010.

[72] R. M. El Backly and R. Cancedda, "Bone marrow stem cells in clinical application: harnessing paracrine roles and niche mechanisms," Advances in Biochemical Engineering/Biotechnology, vol. 123, pp. 265-292, 2010.

[73] I. McNiece, J. Harrington, J. Turney, J. Kellner, and E. J. Shpall, "Ex vivo expansion of cord blood mononuclear cells on mesenchymal stem cells," Cytotherapy, vol. 6, no. 4, pp. 311317, 2004.

[74] N. Nakao, T. Nakayama, T. Yahata et al., "Adipose tissuederived mesenchymal stem cells facilitate hematopoiesis in vitro and in vivo," American Journal of Pathology, vol. 177, no. 2, pp. 547-554, 2010.

[75] A. V. Vanikar, H. L. Trivedi, A. Feroze, K. V. Kanodia, S. D. Dave, and P. R. Shah, "Effect of co-transplantation of mesenchymal stem cells and hematopoietic stem cells as compared to hematopoietic stem cell transplantation alone in renal transplantation to achieve donor hypo-responsiveness," International Urology and Nephrology, vol. 43, no. 1, pp. 225$232,2010$.

[76] W. A. Noort, A. B. Kruisselbrink, P. S. In't Anker et al., "Mesenchymal stem cells promote engraftment of human umbilical cord blood-derived CD $34^{+}$cells in NOD/SCID mice," Experimental Hematology, vol. 30, no. 8, pp. 870-878, 2002.

[77] I. R. Lemischka, "Microenvironmental regulation of hematopoietic stem cells," Stem Cells, vol. 15, no. 1, pp. 63-68, 1997.

[78] M. Angelopoulou, E. Novelli, J. E. Grove et al., "Cotransplantation of human mesenchymal stem cells enhances human myelopoiesis and megakaryocytopoiesis in NOD/SCID mice," Experimental Hematology, vol. 31, no. 5, pp. 413-420, 2003.

[79] D. H. Kim, K. H. Yoo, Y. S. Yim et al., "Cotransplanted bone marrow derived mesenchymal stem cells (MSC) enhanced engraftment of hematopoietic stem cells in a MSC-dose dependent manner in NOD/SCID mice," Journal of Korean Medical Science, vol. 21, no. 6, pp. 1000-1004, 2006.

[80] C. L. da Silva, R. Gonçalves, K. B. Crapnell, J. M. Cabral, E. D. Zanjani, and G. Almeida-Porada, "A human stromal-based serum-free culture system supports the ex vivo expansion/maintenance of bone marrow and cord blood hematopoietic stem/progenitor cells," Experimental Hematology, vol. 33, no. 7, pp. 828-835, 2005.

[81] R. Gonçalves, C. L. da Silva, J. M. S. Cabral, E. D. Zanjani, and G. Almeida-Porada, "A Stro- $1^{+}$human universal stromal feeder layer to expand/maintain human bone marrow hematopoietic stem/progenitor cells in a serum-free culture system," Experimental Hematology, vol. 34, no. 10, pp. 1353-1359, 2006.

[82] N. G. Chung, D. C. Jeong, S. J. Park et al., "Cotransplantation of marrow stromal cells may prevent lethal graft-versus-host disease in major histocompatibility complex mismatched murine hematopoietic stem cell transplantation," International Journal of Hematology, vol. 80, no. 4, pp. 370-376, 2004.

[83] O. Gurevitch, T. B. Prigozhina, T. Pugatsch, and S. Slavin, "Transplantation of allogeneic or xenogeneic bone marrow within the donor stromal microenvironment," Transplantation, vol. 68, no. 9, pp. 1362-1368, 1999.

[84] A. Stanevsky, A. Shimoni, R. Yerushalmi, and A. Nagler, "Cord blood stem cells for hematopoietic transplantation," Stem Cell Reviews and Reports, vol. 7, pp. 425-433, 2011.

[85] M. Battiwalla and P. Hematti, "Mesenchymal stem cells in hematopoietic stem cell transplantation," Cytotherapy, vol. 11, no. 5, pp. 503-515, 2009.

[86] K. Sugiura, H. Hisha, J. Ishikawa et al., "Major histocompatibility complex restriction between hematopoietic stem cells and stromal cells in vitro," Stem Cells, vol. 19, no. 1, pp. 46-58, 2001.

[87] R. Abdi, P. Fiorina, C. N. Adra, M. Atkinson, and M. H. Sayegh, "Immunomodulation by mesenchymal stem cells: a potential therapeutic strategy for type 1 diabetes," Diabetes, vol. 57, no. 7, pp. 1759-1767, 2008.

[88] R. E. Newman, D. Yoo, M. A. LeRoux, and A. DanilkovitchMiagkova, "Treatment of inflammatory diseases with mesenchymal stem cells," Inflammation and Allergy-Drug Targets, vol. 8, no. 2, pp. 110-123, 2009. 
[89] M. Krampera, S. Glennie, J. Dyson et al., "Bone marrow mesenchymal stem cells inhibit the response of naive and memory antigen-specific T cells to their cognate peptide," Blood, vol. 101, no. 9, pp. 3722-3729, 2003.

[90] F. Dazzi and F. M. Marelli-Berg, "Mesenchymal stem cells for graft-versus-host disease: close encounters with T cells," European Journal of Immunology, vol. 38, no. 6, pp. 1479-1482, 2008.

[91] K. Le Blanc, I. Rasmusson, C. Gőtherstrőm et al., "Mesenchymal stem cells inhibit the expression of CD25 (interleukin-2 receptor) and CD38 on phytohaemagglutininactivated lymphocytes," Scandinavian Journal of Immunology, vol. 60, no. 3, pp. 307-315, 2004.

[92] A. Corcione, F. Benvenuto, E. Ferretti et al., "Human mesenchymal stem cells modulate B-cell functions," Blood, vol. 107, no. 1, pp. 367-372, 2006.

[93] K. English, F. P. Barry, and B. P. Mahon, "Murine mesenchymal stem cells suppress dendritic cell migration, maturation and antigen presentation," Immunology Letters, vol. 115, no. 1, pp. 50-58, 2008.

[94] H. Y. Lai, M. J. Yang, K. C. Wen, K. C. Chao, C. C. Shih, and O. $\mathrm{K}$. Lee, "Mesenchymal stem cells negatively regulate dendritic lineage commitment of umbilical-cord-blood-derived hematopoietic stem cells: an unappreciated mechanism as immunomodulators," Tissue Engineering, vol. 16, no. 9, pp. 2987-2997, 2010.

[95] S. Pulavendran, J. Vignesh, and C. Rose, "Differential antiinflammatory and anti-fibrotic activity of transplanted mesenchymal vs. hematopoietic stem cells in carbon tetrachloride-induced liver injury in mice," International Immunopharmacology, vol. 10, no. 4, pp. 513-519, 2010.

[96] D. Polchert, J. Sobinsky, G. Douglas et al., "IFN- $\gamma$ activation of mesenchymal stem cells for treatment and prevention of graft versus host disease," European Journal of Immunology, vol. 38 , no. 6, pp. 1745-1755, 2008.

[97] G. M. Spaggiari, A. Capobianco, S. Becchetti, M. C. Mingari, and L. Moretta, "Mesenchymal stem cell-natural killer cell interactions: evidence that activated NK cells are capable of killing MSCs, whereas MSCs can inhibit IL-2-induced NK-cell proliferation," Blood, vol. 107, no. 4, pp. 1484-1490, 2006.

[98] S. Ghannam, C. Bouffi, F. Djouad, C. Jorgensen, and D. Noël, "Immunosuppression by mesenchymal stem cells: mechanisms and clinical applications," Stem Cell Research and Therapy, vol. 1, no. 1, pp. 2-8, 2010.

[99] A. Chapel, J. M. Bertho, M. Bensidhoum et al., "Mesenchymal stem cells home to injured tissues when co-infused with hematopoietic cells to treat a radiation-induced multi-organ failure syndrome," Journal of Gene Medicine, vol. 5, no. 12, pp. 1028-1038, 2003. 


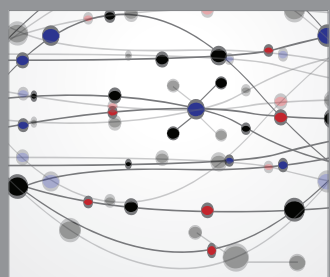

The Scientific World Journal
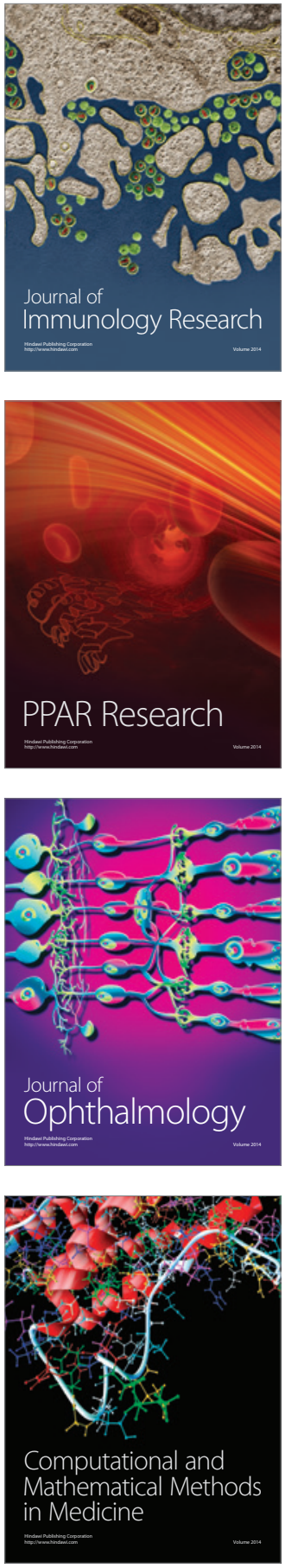

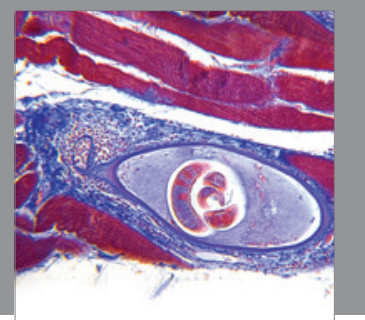

Gastroenterology

Research and Practice
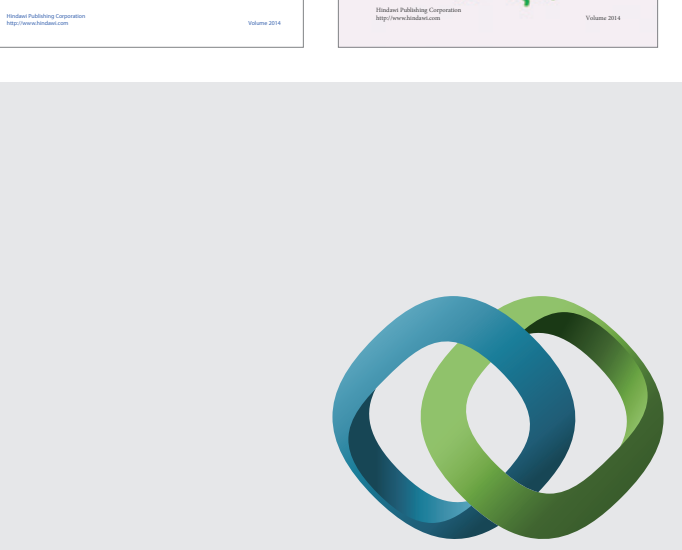

\section{Hindawi}

Submit your manuscripts at

http://www.hindawi.com
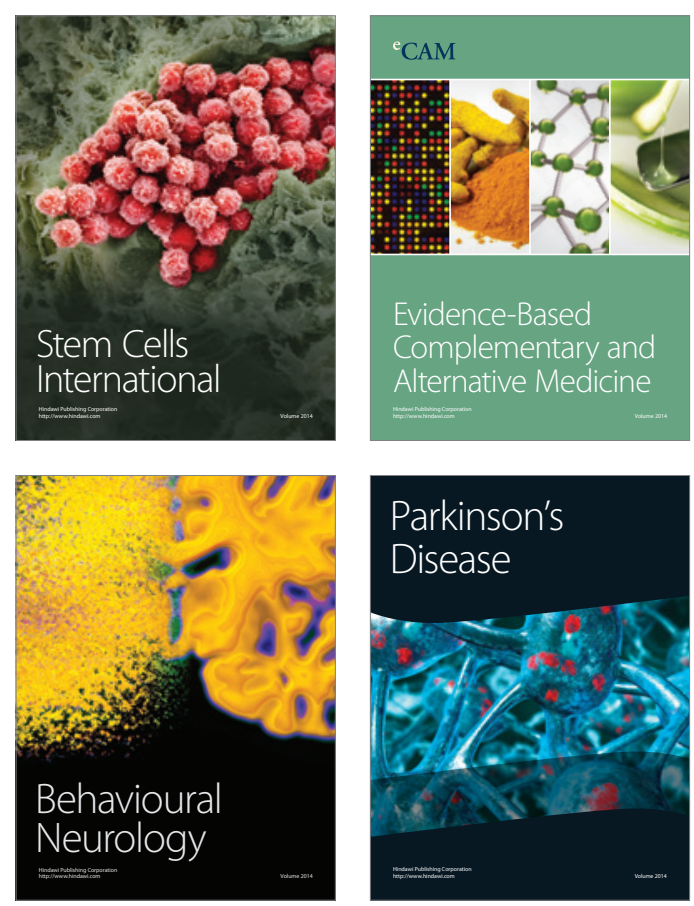

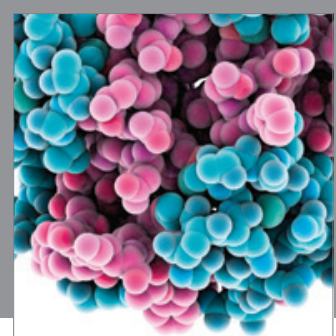

Journal of
Diabetes Research

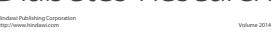

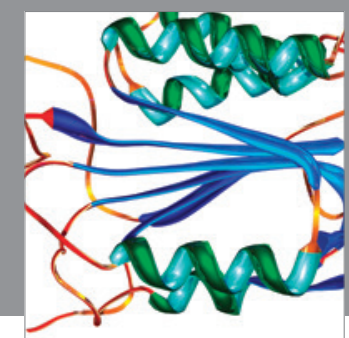

Disease Markers
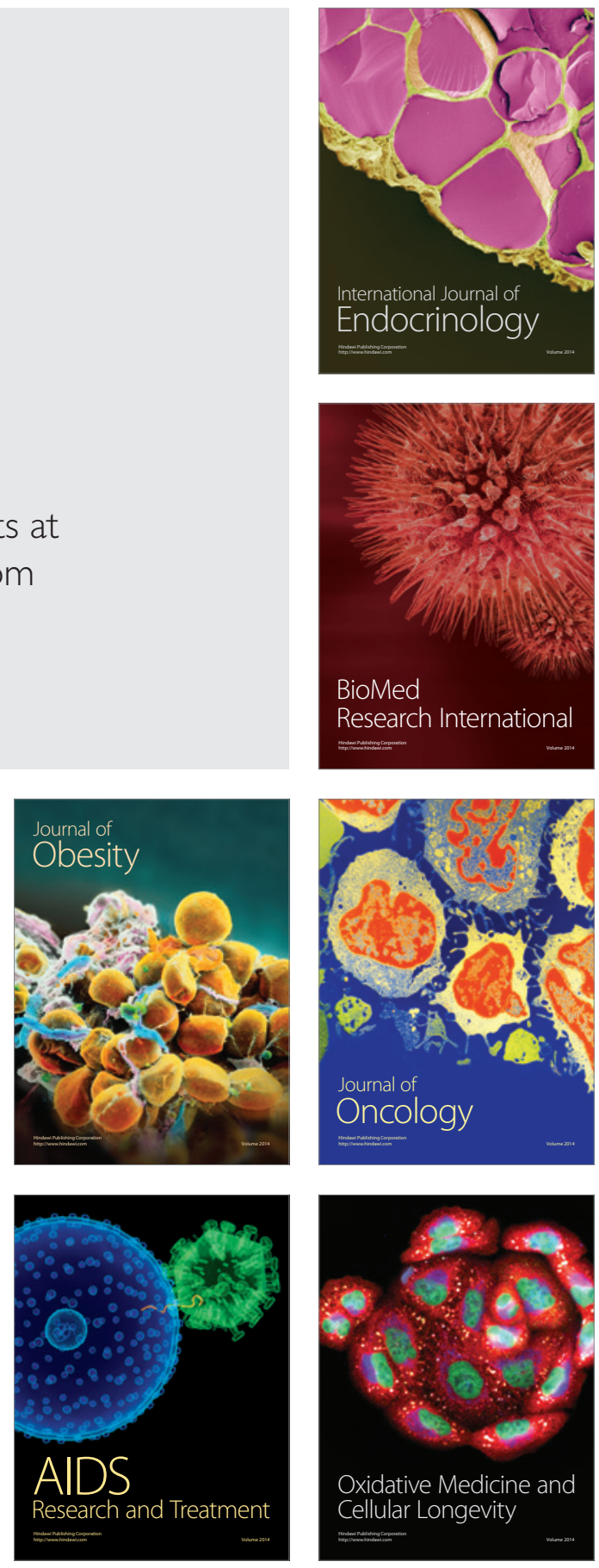